\title{
Presentación \\ ESCRITORAS LATINOAMERICANAS EN EL SIGLO XXI: CUESTIONES LÍQUIDAS
}

Los trabajos que reúne este dossier ofrecen una aproximación a las escritoras latinoamericanas durante el siglo XXI. Las luchas feministas contemporáneas que alcanzaron su auge a finales de los años sesenta y de los años setenta, así como el post-boom latinoamericano de los años ochenta y noventa, propiciaron una visibilidad significativa de la escritura de mujeres. A su vez, esta visibilidad se extendió a través de las editoriales que, por razones comerciales, empezaron a promover a un mayor número de escritoras que atendían a un público "femenino" de lectoras. Sin embargo, el canon literario seguía siendo predominantemente masculino. De ahí que los primeros veinte años del presente siglo son sustanciales para comprender los alcances de las manifestaciones literarias emergentes, en particular las hechas por mujeres en Latinoamérica. En comparación con el siglo anterior, en el siglo XXI cada vez más escritoras latinoamericanas se posicionan en los circuitos literarios, con una mayor participación en el mercado editorial y en las ferias literarias con obras que van más allá de la visión reduccionista masculino/femenino. Asimismo, las escritoras tienen más presencia en los medios de comunicación masiva, gracias al internet y a las redes sociales. No obstante, aún queda trabajo por hacer. Por ejemplo, para el festival "Hay" de Cartagena en 2017, las treinta y nueve "voces para contar Latinoamérica" incluyen trece mujeres y veintiséis hombres. Es decir, el número de hombres duplicaba al de mujeres. Pero más allá de los números, los temas de la violencia de género siguen más presentes que nunca; en consonancia con los movimientos de Ni Una Más y Me Too, donde activistas y escritoras han denunciado el acoso y la violencia sexual en sus esferas sociales.

Las escritoras contemporáneas que se estudian en este dossier no se reconocen como parte de una generación coherente y con fines comunes. Sin embargo, levantan la voz para compartir sus experiencias y narrar sobre temas que anteriormente resultaban tabúes. En particular, su escritura es un 
acto literario que desafía sus continentes referenciales. No solo cuestiona prácticas enraizadas en el siglo pasado, sino que se construye con variaciones constantes, como producto de una era de intercambios y movilidades intensas. Las pertenencias nacionales y sus formas se discuten o se omiten. Parecería que entramos a una época de nomadismos y circulaciones impostergables, la cual también es acompañada de una lluvia ácida poco generosa, llamada mercado neoliberal.

En el primer artículo, “Maternidades 'líquidas': feminismos y narrativas recientes en Chile', Lorena Amaro aborda cómo el tema de la maternidad ha cambiado durante y después de la dictadura chilena (1973-1990). De autoras que ven a la maternidad desde lentes ficcionales y monstruosos, como Diamela Eltit y Pía Barros, se pasa a la comparación de las escritoras contemporáneas Lina Meruane y Claudia Apablaza. En Contra los hijos, Meruane critica los discursos maternales, mientras que en Diario de quedar embarazada, Apablaza aboga por maternidades gozosas. Lo cierto es que, tal como lo apunta Amaro, ambas cuestionan las exigencias de las maternidades modernas y buscan nuevas respuestas fuera de los límites patriarcales.

En el siguiente artículo, "Leer-nadar: rocío de la introspección y placer amniótico en la poesía de Alicia Genovese", Nadia Prado estudia las formas en que la poeta Alicia Genovese emplea el tropo del agua para hacer eco de la memoria. La poeta aborda el caso de la nadadora argentina María Inés Mato o de las personas fallecidas durante la guerra de las islas Malvinas. Lo líquido sirve para hablar de la introspección y de travesías que están atravesadas por proezas, pero también por heridas abiertas.

En el tercer artículo, "La fragilidad de las fronteras corporales", Paula Daniela Bianchi analiza "Janice e o umbigo" (2003) y "200 m" (2010) de la brasileña Veronica Stigger, "Un hombre sin suerte" (2015) de la argentina Samanta Schweblin, "Perro callejero" (2009) de la boliviana Giovanna Rivero y "Hongos" (2013) de la mexicana Guadalupe Nettel. Estos relatos tienen en común que sus personajes expresan el efecto que tiene en sus cuerpos el hacer frente a experiencias anómalas. Es decir, la piel denuncia la violencia del exterior, donde los personajes se autoimponen la introspección y el aislamiento. El espacio líquido de sus cuerpos, tal como lo identifica Bianchi, se vuelve un espacio sórdido y baldío.

En el último artículo, "Mujeres imaginando nuevas cartografías en la Argentina del post-milenio", María José Punte estudia En el hotel cápsula (2017) de Lucía Puenzo, Algún lugar (2017) de Paloma Vidal y V (2017) de Mariana Docampo. En estas autoras argentinas, Punte explora cómo 
perciben los personajes espacios citadinos como Tokio o Los Ángeles fuera de los bordes nacionales y temporales, y cómo estos establecen cartografías emocionales. Asimismo, se identifican personajes que desde el tránsito cuestionan las diversas caras de los cosmpolitanismos.

Los artículos que se presentan retoman la propuesta de "modernidad líquida" de Zygmunt Bauman, y desde un enfoque crítico de sexo y género, cuestionan cómo la literatura escrita por latinoamericanas incorpora las experiencias de vida, junto a los flujos de violencia y de capital; flujos que se inscriben en las incertidumbres performativas de sociedades más interconectadas, pero en condiciones de mayor precariedad. Este dossier propone reflexiones acerca la literatura publicada por escritoras latinoamericanas en estos primeros veinte años del siglo XXI. La intención ha sido la de generar puntos de vista múltiples, señalar itinerarios, coincidencias, cancelaciones y búsquedas.

LOURDES PARRA-LAZCANO Universidad de Aberdeen, Aberdeen, Escocia

MAuricio Díaz CALDERÓN Universidad de Guadalajara, Guadalajara, México

Coordinadores dossier Escritoras latinoamericanas en el siglo XXI: cuestiones líquidas 